\title{
GOD SE WOORD DIE MODERNE ANTWOORD*
}

\author{
Prof. J. J. van der Walt
}

DIE vraag waarvoor $u$ opdrag ons gestel het, is: kán, en hoe kan, die diens van ouderlinge en diakens Bybels én modern wees?

Dit wek dankbare vreugde dat daar met entoesiasme aandag gegee word aan die diens van ouderlinge en diakens in die kerk. Want dit maak die kerk weerbaar teen 'n dubbele gevaar wat, in omgekeerde eweredigheid, die kerk in die moderne tyd bedreig: onmondigheid van lidmate (wat ouderlinge en diakens insluit) kweek predikanteheerskappy.

En daar is rede tot kommer oor onmondigheid wanneer die kerk nog entoesiasme opwek vir sake van eie gerief (matte, verwarming, kerkbou) maar koud en ongeroerd bly in die roeping om vir die Evangelie te getuig. Hierin wil die daadkrag maar net nie op ' $n$ breë front ontluik nie. Die gemoedere kom in beweging wanneer êrens 'n woord gesê word wat lyk na politieke kettery; teen God moet daar baie ernstig en uitdagend gesondig word voordat dit dieselfde emosie in verontwaardiging ontlok.

'n Kerk waarin godsdienstige onmondigheid heers, sal nie die storms wat op Suid-Afrika, en dus op die kerk in Suid-Afrika, afstuur, kan trotseer nie. Want 'n kerk is gelyk aan die gelowiges wat dit vorm en nie gelyk aan woorde, baie woorde, in sinodale handelinge waarvan die lidmate niks of weinig kennis neem nie.

\section{Die moderne tyd}

Dit is nodig dat ons vooraf enkele oriënterende opmerkings maak oor die begrip "moderne tyd". ,Moderne tyd" is 'n samevatting van die heersende omstandighede, die probleme wat daaruit voortvloei en die uitwerking wat dit het op die mens.

Die volgende uitstaande kenmerke van die moderne tyd, soos ons dit as Gereformeerdes in Suid-Afrika belewe, kan aangesip word:

$\diamond$ Voortgaande verstedeliking, met al die sosiale en ekonomiese en etiese vraagstukke wat met die lewe in die grootstad gepaard gaan.

$\diamond$ Die geweldige ontploffing van kommunikasie deur pers, radio en televisie, wat paradoksaal juis die mens se eensaamheid geweldig geïntensifiseer het.

$\diamond$ Gepaard met groter kommunikasie gaan ook groter wêreldspanning en dreiging van geweld. Tegelykertyd word rassisme op die spits gedryf, met Suid-Afrika in die midde van wêreldaandag.

$\diamond$ In die gespanne wêreld met sy sosiale godsdiens raak die kerk al minder en minder van 'n faktor. Buite Suid-Afrika het die proses reeds sover gevorder dat algemeen, in eens Christelike lande, gepraat word van ,'n na-Christelike tyd”. Ons word deur 
baie Christene van ortodokse belydenis bevoorreg geag dat ons in Suid-Afrika nog 'n land en Regering het wat christelik gerigd is.

$\diamond$ Die modewoord in die hedendaagse politiek oor die Westerse wêreld en die Derde Wêreld is: demokrasie, in die sin van een-man-een-stem. As 'n metode om die aandag van eie politieke omstandighede weg te projekteer, word die eis met dubbele standaarde juis in sy uiterste vorm aan Suid-Afrika gestel.

$\diamond$ Die boosheid, die ontsaglike verdierlikende verwording van die sedelike lewe van die mens neem hand oor hand toe. Homoseksuele ontaarding het 'n dringende pastorale probleem geword, en dit nie langer net buite Suid-Afrika nie.

$\diamond$ 'n Mens moet baie onbetrokke lewe as jy nie besef dat die ryk van die Antichris vinnig rondom ons opbou nie. Die grootste en dringendste stryd is nie meer oorlewing van eie volk en staat nie, maar oorlewing van die geloof en die kerk in 'n ontkerstende wêreld. Vir ons is die twee, genadiglik, nog nou verbonde. Maar die voorrang kom die kerk toe. Ons ervaar die ontsaglike ontplooiing van die mens se mag in wetenskaplike tegnieke sodat dit al vir ons verstaanbaar word dat 'n mens, die Antichris, in die tempel sal sit en as god aanbid sal word omdat hy verbysterende wonders doen.

\section{Die moderne Bybel}

Die Bybel beskrywe en beoordeel en beantwoord al die trekke en vrae van die moderne tyd. God se Woord gee die mees moderne antwoord. 'n Mens kan ons tyd op geen ander manier deurgrond as om dit in die lig van die Bybel te besien nie. Die Bybel is die moderne tyd selfs vóor, want dit sê wat ons moet verwag, in tyd en ewigheid.

Kom ons let op enkele voorbeelde:

Ons maak daarvan 'n groot belangrikheid dat ons jeug onder uiters moeilike en verleidende omstandighede opgroei. 'n Belangrike Gereformeerde Opvoedkundige sê dat hy daarom ons jeug intens jammer kry - hulle moet te midde van soveel sedelike verwording volwasse word. Dit is waar: ons jeug word van alle kante bestorm met skaamteloosheid. Maar dié bestorming van die kerk vind nie nou vir die eerste keer of in die eerste graad plaas nie. Dink aan die kerkjeug in die stad van Korinthe in die dae van Paulus. Ons tyd kan nie aanspraak maak op groter verwording as dié wat Paulus beskrywe in Rom. 1 en 1 Kor. 5 nie. En nog veel vroeër in die openbaringsgeskiedenis lees ons van die jongman Josef, 'n vreemdeling in ' $n$ heidenland, onder die uiterste provokasie geplaas deur die vrou van Potifar. Dáár gee die Bybel reeds die aller modernste antwoord teen die aanslag van die Bose op ons jeug: "hoe kan ek hierdie groot kwaad doen en sondig teen God" (Gen. $39: 9$ ).

'n Volgende ,moderne" probleem waarvan ons baie hoor is: die generasiegaping. 
kommer.

Dit besorg ouers en opvoedkundiges en sielkundiges groot

Waarom ruk dié verhouding so hande-uit? Daar was tog altyd ouers cn kinders. Omdat ons die altyd moderne voorskrif van God in Deut. 4 : 11 nie noukeurig in ag neem nie:

$\diamond$ liefde tot God moet ons lewe beheers;

$\diamond$ die liefde is 'n praktiese lewenswyse.

„En hierdie woorde wat ek jou vandag beveel, moet in jou hart wees; en jy moet dit jou kinders inskerp en daaroor spreek as jy in jou huis sit en as jy op pad is en as jy gaan lê en as jy opstaan. Ook moet iy dit as teken bind op jou hand, en dit moet as 'n voorhoofsband tussen jou oë wees. En jy moet dit op die deurposte van jou huis en op jou poorte skrywe" (Deut. $6: 4-9$ ).

Die lewe met God waarmee 'n gelowige die werklikheid van die godsdiens vir sy kind moet inskerp, moet by die opgroei van die kind nie vergeet word nie (vers 12), want dit is die basis waarop die gaping oorbrug word dié dag wanneer die kind vra: „Waarom?"”

„En as jou seun jou later vra en sê: Wat beteken die getuienisse en die insettinge en die verordeninge wat die Here onse God julle beveel het?, dan moet jy aan jou seun sê: ... die Here..." (Deut. 6 : 20-25). Die geskiedenis spel: die Here, die Verbondsgod. Hy bind die geslagte saam.

Die geslagte wat uit Egipte getrek het en die geslagte wat in Kanaän opgegroei het, het die één brug gehad oor die gaping tussen hulle. Wanneer ons kinders vra: Waarom, midde in ons rassespanning, geloftedagviering? Dan het ons net één sinvolle antwoord: die HERE. Dit is dié moderne manier om die harte van vaders en seuns by mekaar te bring.

Ons kan hierby nie te lank vertoef nie. Genoeg is gesê om aan te toon: die Bybel gee die moderne antwoord. Ons moet dit maar noukeurig daar soek. Die Christelike kerk en die ampsbediening in die kerk, is nie afhanklik van die middels wat ons tyd so graag aanbied nie. Die aanspraak dat die ampsbediening nie sonder die moderne Sielkunde en Psigiatrie en Sosiologie en Filosofie die mas kan opkom nie, is geheel en al oordrewe en 'n miskenning van die genocgsaamheid van die Skrif. (Die bykomende hulpdiens van 'n Christelike beoefening van die vertakkinge van die wetenskap word nie misken nie). As 'n voorbeeld kan die liturgie dien: Die aandrang om die Liturgie te moderniseer om aan te pas by die moderne mens se vermaaklikheidservaringe. Die erediens is nie 'n vermaaklikheid nie. En die diens van God kan niks méér modern wees as die erediens wat vanaf die paradys bestaan nie: luister en aanbid.

Daarom moet die ampsbediening die moderne wêreld aandurf met die Bybel wat aller moderns is.

Die moderne tyd mag ons nie beangs, verward of verskrik laat nie. En dit sal ook nie as ons die nuwe tyd sien as die tyd van die heerskappy van ons Here Jesus Christus en die inwoning van die Heilige Gees in ons nie. Die moderne tyd is niks anders 
as 'n nuwe tyd wat binne die laaste bedeling oopgaan vir die koninkryk van God nie. Dink aan die aanvang van die nuwe bedeling daar langs die Jordaan toe Johannes die Doper meteens met sy vinger gewys en vir die mense gesê het: "Daar is die Lam van God wat die sonde van die wêreld wegneem" (Joh. $1: 29$ ). Dink: watter nuwe tyd breek dáár oor die mense oop. En hoe min het hulle daarvan verstaan! Selfs toe Jesus Self begin spreek met die aankondiging: „Die tyd is vervul..." (Mark. 1: 15). Die ou tyd is vol, verby. 'n Nuwe tyd is hier..., ,en die koninkryk van God het naby gekom". Ons lewe ook in dié nuwe tyd van die koninkryk wat met Jesus gekom het en met sy wederkoms voltooi sal wees. Dit is dan die ontplooiing van die koninkryk van God wat voltrek word in die ontwikkeling van die geskiedenis. Wat ook al nó oor ons oopbreek, in die moderne tyd, beteken eindelik net één ding: 'n nuwe ontplooiing in die koms van die koninkryk van God; 'n nuwe deur gaan oop. Ons moet bid dat ons daarvoor nie so blind sal wees soos die mense rondom Johannes die Doper nie.

Laat ons byvoorbeeld die Franse Rewolusie in perspektief sien. Ons gedagtebeeld daarvan is: verskrikking, moord, liberalisme. En dit hét verskrikking deur die regimente van die Christelike kerk gejaag. Maar: deur die ontwikkelinge van die rewolusie beskik God vir die kerk die vrywording van die gewone mens uit die slawebande van die hiërargie sodat die Evangelie ruimte kry in die samelewing, 'n vryheid van spraak en geloof, wat beteken vryheid om die Evangelie te verkondig en te bely op alle lewensterreine.

Daarom: in ons moderne situasie moet ons nie ons blik net op één punt vastrek nie. Dit lyk wel seker dat ons besittings, ons ou volktradisies, ons lewenspatroon, ons politieke magsposisie, selfs ons lewe, in gedrang kan kom. Kom ons wees nugter, met 'n Bybelse nugterheid: daar is baie dooie hout in ons lewensboom wat uitgekap moet word - selfs in ons kerklike lewe is daar diepsondige gewoontes wat radikaal moet verander, soos bv. ons onverskilligheid teenoor die aanddienste. Die dooie hout moet uit. Dit strem die groei van die boom. Bo alles moet uitgroei die nuwe lewe wat opgroei uit die roeping waarmee God ons roep in die nuwe tyd, met sy nuwe geleenthede, om te dien as mede-arbeiders in die ontplooiing van sy koninkryk. Ons gevoel van weerloosheid stam uit die feit dat ons nie aan ons tyd die regte vraag stel nie: watter geleenthede gaan oop vir die Evangelie? Hoe kan die kerk - ouderlinge en diakens en lidmate en dominee en professor - juis nou die koms van die koninkryk van God dien?

Die eenvoudige antwoord op dié vraag aan die moderne tyd bly dieselfde as in die prediking van Jesus: „Bekeer julle en glo die evangelie" (Mark. 1 : 15). Elke antwoord wat werklik sin het, sal 'n onderdeel wees van dié grondliggende antwoord. Want bekering en geloof sit jou aan die werk om in jou eie omstandighede te werk vir die koninkryk wat kom, en om nie te kleef aan 'n lewe wat verbygaan nie. En ek meen die roeping wat vir ons in SuidAfrika sentraal staan, is om Christus te dien in die naasbestaan van volke deur aan mekaar volle lewensruimte te gun en te gee. Die groot les van ons eie moderne geskiedenis word steeds duide- 
liker: alleen binne die koninkryk van God en sy geregtigheid is daar 'n versekerde lewensbehoud.

\section{Die ampsbediening}

\subsection{Die orde in die kerk}

Die ampte is gawes van die Here in die kerk. Dit is nie die enigste gawes waarmee die Here die bestaan van die kerk verseker nie. Maar deur die ampte gee die Here orde en struktuur aan sy kerk, en daarmee vermoë om diensbaar te wees. Want deur die ampte stig God orde in sy kerk. Hierdie orde is egter méér as goeie organisasie. Die klassieke teks waarin dit geopenbaar word, is 1 Kor. $14: 33-40$ : „Maar God is nie 'n God van wanorde nie, maar van vrede, soos in al die gemeentes van die heiliges ... Laat alles ordelik en welvoeglik toegaan". Ons moet goed oplet wat stel die Bybel hier teenoor mekaar. In ons logika sou ons teenoor ,wanorde" (vs. 33) orde gestel het. Maar die Bybel stel „vrede" teenoor ,wanorde". Vrede wis wanorde in die kerk uit. Die orde wat God in die kerk wil stig deur die gawe van die ampte is die orde van vrede. Orde in die kerk is die harmonie wat daar is in die organiese eenheid van die kerk met sy Here, en die eenheid van die gelowiges as lede van een liggaam. Die orde en vrede van die kerk is die lewenseenheid van Hoof (Christus) en liggaam (kerk), want Christus is ons vrede (Ef. $2: 14$ ). 'n Lewe na die Woord van God dryf die wanorde uit die kerk uit en stig vrede met God en met mekaar. Dit is die lewe wat Christus vir die kerk bepaal.

\subsection{Die taak van die ouderling en diaken}

3.2.1. In die totstandbrenging en voortgang en opbloei van die orde en vrede in die kerk is die ouderlinge en diakens diensknegte. Die Bybel het geen ander woord as „diensknegte" om ampsdraers te beskrywe nie. En daar is geen ander manier om ampswerk te doen, en om die probleme van die moderne tyd aan te pak, as dat die ampsdraers diensknegte sal wees nie. Die kerk het net één Hoof, selfs geen onderhoof nie. Jesus Christus is die Hoof van die liggaam, die kerk (Kol. 1 : 18). Die ouderlinge, diakens, predikante, lidmate, professore is almal lede van die liggaam. Daar is geen tussenposisie tussen Hoof en liggaam nie. In die liggaam is een lid nie oor die ander gestel nie, en geen lid kan sonder die ander lede klaarkom nie. Die fout van die Roomse (en elke hiërargie) is dat dit 'n lid bo die ander lede stel en so Christus met ' $n$ mens verdring. Daarom is die enigste wyse waarop die ampte "modern" kan werk: om diensknegte te wees. Deur mekaar te dien, dien die lede die Hoof. Alle ampswerk moet die wil van die Hoof volbring en sy gawes bedien, die aandag op Hom vestig en nooit die bedienaar voorop stel nie. Vir die dienaar moet Jesus se woorde konkreet, praktyk, wees: „Wie agter My aan wil kom, moet homself verloën en sy kruis opneem en My volg" (Mark $8: 34$ ). Goeie ampswerk verloop soos wanneer iemand twee persone aan mekaar voorstel wat onmiddellik so 'n geesverwantskap ervaar dat die voorsteller ver. 
gete is. 'n Egte ampsdraer werk so dat hy verdwyn agter die Hoof van die kerk wat hy na vore bring in sy bediening. Die antwoord in die ampswerk op al die probleme van die moderne tyd is om die moderne mens te bring by sy Here.

Dit is moontlik om allerlei middels, allerlei slenters in te span om 'n kerk kunsmatig in stand te hou en na die uitwendige - getalle, strukture, geboue - op te bou. Die magtige Roomse kerk bestaan reeds eeue in sy dooie uitwendigheid. Maar as die ampsdraers die lidmate nie by God bring deur Jesus Christus nie, is alles tevergeefs. Daarom is die ampsdraer 'n dienskneg van die Woord van die Here. Daarmee bring hy die lidmate by die Here, en stel hom saam met hulle onder sy gesag. So dien hy die lidmate. 1 Petr. 5 : 2, 3 meet vir ons die taak van die dienaars in die kerk duidelik af: nie heers nie (vgl. Luk. $22: 25,26$ ) maar ' $n$ voorbeeld wees. Die Bybel ontneem aan die ampte elke sweem van die posisie van 'n owerheid oor onderdane. Dien, dit is die enigste manier waarop die amp effektief-modern, kan werk.

Dit sluit ten volle aan by die doel van die ampte soos dit vasgestel word in Ef. $4: 11,12$. Die Here het die ampte gegee „om die heiliges toe te rus vir hulle dienswerk". Die mondigheid van die lidmate moet erken en bevorder word, en mag nooit misken en ondermyn word nie. Daarom is die diens van predikant, ouderling en diaken tydelik, die diens van die gelowige ewig.

3.2.2. Die indruk is sterk anwesig dat die mondigheid van die gelowiges nie kragtig en doelgerig genoeg bevorder word nie. Dit kan alleen daartoe lei dat die paraatheid van die kerk in die moderne tyd verswak word. Baie van ons sal nog uit ons jeug herinner hoe daar gereeld gemeentevergaderings gehou is om sake van belang te bespreek. Dit kan gebeur omdat die kerkraad die advies van die gemeentelede soek, of omdat 'n saak (bv. kerkbou of nie; koevertstelsel of nie) vir beslissing voorgelê word. In baie kombinasie-gemeentes het ouderlinge vir tientalle jare met hoë verantwoordelikheid en mondigheid dienste en katkisasie gehou. Die kerkraad is voorgangers. Hulle moet die gemeente saamneem en nie beveel nie; nie alles klontjie-klaar beklink, en dan die gemeente net aansê wat om te doen nie. Só word die heiliges nie toegerus vir hulle dienswerk nie. Onder so 'n bediening volgens owerheidsmodel moet die belangstelling van die lidmate kwyn en die betrokkenheid by die kerk later verdwyn. Daarom praat die treurige gesukkel om kerkraadslede te $\mathrm{kry}$, en om verkiesingsvergaderings noodwendig vóór die erediens te hou, in harde taal.

Wanneer die bediening nie meer doelbewus daarop gerig is om die mondigheid (en dus betrokkenheid) van die gelowiges by die kerklike sake te erken en op te bou nie, sal die kerk al meer en meer 'n leë dop word. Ons moet let op die vingerwysing in swak kerkbesoek, want die resultaat van 'n gebrek aan betrokkenheid is. Paulus het hom op die mondigheid en betrokkenheid van die gelowiges beroep (1 Kor. $10: 15$ ). En watter amp kan meer wees as die van die apostels? In hulle mondigheid het die gelowiges opdragte ontvang wat in die.Naam van Christus volbring moet word. Dit 
behels selfs kerkregering wat met gesag uitgevoer word. Hieronder tel o.a. die kiesreg (Hand. $1: 15,23 ; 6: 1 ; 14: 26 ; 20: 28 ; 1$ Tim. 4 : 4), deelname in die tuguitoefening (2 Thess. $3: 6,14 ; 1$ Kor. 5 : 5), mede-oordeel oor finansiële beplanning, bouprogramme, liturgiese veranderinge en lidmaatskap.

In 'n kerk met mondige lidmate is dit verkeerd en oortollig dat 'n ,vriendelike" predikant of ouderling in allerhaas moet bel om te hoor of die broeder (suster) „maar mag nagmaal gebruik". Wie durf dié vraag beantwoord? Geen predikant of ouderling sal tog op eie houtjie in 'n gemeente 'n lidmaat toelaat of afhou nie! Die lidmaat moet - dit is die korrekte weg - in mondige verantwoordelikheid self betyds sorg dat hy van die kerkraad die nodige getuienis het. Dit moet 'n mondige lidmaat grief as sy sake uit sy hand geneem word asof hy 'n kind is.

'n Kommissiegewys-pragtig-georganiseerde gemeente is nog nie 'n mondige gemeente nie. Die oorbeklemtoning van meganiese organisasie sê juis die organiese lewe is aan 't sterwe. Die gladgeoliede masien van georganiseerde aktiwiteite is dikwels ook so dood soos 'n masjien. 'n Gemeente van Christus lewe in geloof en liefde, wat van binne af die daad uitdring. Goeie gemeenteorganisasie gaan nie verder as om dié lewensdrang te stimuleer, te lei en te rig nie. Kerklike aktiwiteit het eers waarde as dit vrye diens van God is, gemeenskap met Gol Self is. Daarom is die swakste ampsbediening dié waarin die ampsdraer vir die lidmat onmisbaar geword het.

Om sy doel te bereik, moet die bediening getrou bly aan die opdrag van die Here. Die opdrag bepaal wat hy mag en moet doen. Die opdrag word duidelik gegee in 1 Petr. $5: 2$ : ,wees 'n herder in die kudde van God". Hierin word alles saamgevat wat in die Nuwe Testament aan 'n ouderling opgedra word. Hand. $20: 28,31$ stel dit meer uitgebreid: „Gee ag op die kudde... waak”. Joh. 21 : 15-17 stel dit: wei, pas die skape op. Ons weet uit die geskiedenis van Dawid (en ander Bybelse herders) wat dit inhou: hy het die leeu en die beer verslaan wat die kleinvee wou aanval. En Jesaja 40 : 11 hou aan ons die innige beeld voor van die herder wat sy kudde laat wei, die lammers in sy arms dra en die lammerooie saggies lei. Elkeen word na sy eie aard en behoefte versorg! Die herder is nie 'n drywer nie. Dit straal ook uit Psalm 23.

Die Here Jesus Self sê in Joh. 10:4 sy skape volg hom omdat hulle sy stem ken; en die Herder roep sy skape by die naam... Hy kén hulle. In Luk. $5: 4-7$ teken Hy die herder wat die verlore skaap soek totdat hy dit kry. Dié volle skriftuurlike beeld van die herder lê opgesluit in die opdrag aan die ouderling: wees 'n herder.

Die opdrag van die diaken is die duidelikste in Hand. $6: 3$, waar verwys word na "die nodige saak" wat konkreet die versorging van die weduwees behels. In samehang met Hand. 2 : 45, waar gestel word dat uitgedeel is "volgens wat elkeen nodig gehad het", sien "die nodige saak" op die lewensnode van die lidmate. Die diaken moet dus sorgdra dat daar middele is, en die middele uitdeel. Hy moet ook praktiese lewensnode identifiseer en sorg dat daar vanuit die gemeente die nodige hulp gebied word. Die bevestigingsformulier van diakens verwys na ,armes en ellendiges" 
wat „nie net met uiterlike gawes nie, maar ook met gepaste trooswoorde uit die Woord van God" bedien moet word. Dit wys reeds aan: Diakonale diens omvat baie meer as om warmte en kos en klere te voorsien. Diakonale diens omvat alles wat fisies nodig is om as kind van God te bestaan en voort te bestaan. Dus ook al die hulp wat die Christelike liefde met 'n fisiese daad of gawe kan bied tot behoudenis van 'n ander. Daar kan selfs by 'n ryke barmhartigheidswerk gedoen word.

Laat ons enkele voorbeelde noem: Die kerk van Christus het nie geloofsanonieme alkoholiste-anoniem nodig om in die lewensnood 'n hand van vriendskap aan 'n broeder wat in die greep van alkoholisme is, te bied nie. Daar is ook nie buitengewone en ekstra organisasies in 'n gemeente hiervoor nodig nie. Die Here het dit van die begin af voorsien in die gemeenskap van die gelowiges, en die diakens het die opdrag om die gemeente voor te gaan. 'n Welgestelde, siek en eensaam, kan die liefdesdiens nodig hê van iemand wat 'n ete berei, briewe skrywe, eensaamheid omskep in gemeenskap. Natuurlik, die welgestelde kon dit huur! Maar die Christelike liefde kan dit gee, sodat die welgestelde sy gawe dankbaar vir die koninkryk van God kan laat werk. Die wêreld meet die kerk aan sy barmhartige liefdesdiens. Veél meer: Christus meet met dié maat, soos duidelik blyk uit Matt. $25: 31-46$. Hier stel Hy die diaken op sy pos.

3.2.3. In die laaste plek word die aandag gevestig op die kollegialiteit van die ampte. Dit is van eersterangse belang vir die taak in die moderne tyd.

Die Nuwe Testament praat altyd van ouderlinge en diakens in die meervoud. Ouderlinge in Hand. $14: 23 ; 15: 2 ; 20: 17 ; 21: 18$; Fil. $1: 1 ; 1$ Petr. $5: 1,2$; Tit. $1: 5 ; 1$ Tim. $5: 17$. Diakens in Fil. $1: 1 ; 1$ Tim. $3: 8 ; 3: 12$. Wat die ouderlinge betref, is daar enkele uitsonderinge in die hele Nuwe Testament. In 1 Tim. $3: 2$ en Titus $1: 7$ word van ouderlinge in die enkelvoud gepraat omdat dit daar gaan om die soort, 'n ouderling as ouderling. Die konsekwente meervoud wil sê ons het in die ouderlinge en diakens te doen met 'n korps. In Handelinge word die eerste diakens genoem "die sewe", en in 1 Tim. 4: 14 die ouderlinge "presbiterium", d.i. kerkraad, soos van die apostels as „die twaalf”. Dus: ouderlinge en diakens moet met mekaar saamwerk, in gemeenskap met mekaar werk. Hulle moet mekaar se hande vat en as 'n eenheid werk in die gemeente. Dit staan vierkantig teen individualisme, teen die neiging om alleen op eie houtjie te werk. Soos Spreuke $18: 1$ sê: „Hy wat hom afskei, soek sy eie begeerte; hy bestry alles wat waarlik tot voordeel strek".

Hoe modern het die Here nie sy kerk toegerus om die probleme van vandag die hoof te bied nie. Die wêreld soek spesialisasie, enkelinge wat op enkelvoudige probleme toegespits is. Hoeveel „spesialiste" sou 'n gemeente nie in die groeiende stad van spesialisasie nodig hê nie? Elke ouderling het om en by twintig persone onder sy sorg met ' $n$ verskeidenheid van eiesoortige werk, lewenspatroon en probleme. Waarin moet elke ouderling dan gespesialiseer wees 
om te kan byhou? Maar die Here het vir elke tyd voluit voorsien: Hy gee in elke tyd uit die bonte skakering van lewe 'n korps van ouderlinge, wat mekaar kan aanvul en help, aan die gemeente. Hy gee nie ouderlinge wyksgewys nie, maar gemeentegewys. Hy gee elke ouderling met sý gawes en sý lewenservaring en kennis aan die gemeente as geheel. En só gee $\mathrm{Hy}$ ook die diakens.

Dit beteken in die praktyk dat ouderling $A$ vir ' $n$ probleem wat vir hom vreemd is die hulp kan kry van ouderling B wat daarmee vertroud is. Hier is ' $n$ Raad van toegeruste manne wat saam 'n vreemde probleem kan ondersoek en aanpak. So werk ouderlinge (en diakens) saam, oordeel saam en pak as 'n span die nood van die tyd aan: 'n eenheid van gawes in 'n ryke verskeidenheid, wat God uit die midde van die moderne lewe aan die teenswoordige gemeente gee.

Die ou dinge in God se plan bly die moderne dinge in die lewe.

* Lesing voor 'n saamtrek van ouderlinge en diakens to VerwoerdburgNoord op 14.3.1977. Versprei deur en verkrygbaar in pamfletvorm by die Gereformeerde Kerk Verwoerdburg-Noord. 